\title{
IL-10, HLA-G and Neutrophil Extracellular Traps as Immune Regulators in Recurrent Pregnancy Loss
}

\author{
Marcello Monti* \\ Department of Clinical Medicine and Surgery, "Federico II" University, Naples, Italy \\ *Corresponding author: Marcello Monti, Department of Clinical Medicine and Surgery, "Federico II" University, Naples, \\ Italy
}

\begin{tabular}{|c|}
\hline ARTICLE INFO \\
\hline Received: 彗 April 09, 2020 \\
\hline Published: April 21, 2020 \\
\hline
\end{tabular}

Citation: Marcello Monti. IL-10, HLA-G and Neutrophil Extracellular Traps as Immune Regulators in Recurrent Pregnancy Loss. Biomed J Sci \& Tech Res 27(1)-2020. BJSTR. MS.ID.004456.

\section{ABSTRACT}

Recurrent pregnancy loss is a main reproductive health issue. There are several known causes such as endocrine and structural uterine abnormalities, chromosomal aberrations, genetic variants causing acquired thrombofilia and alloimmune rejection. A normal immunological homeostasis is needed to avoid reject of the fetus. Genetic polymorphisms in IL-10 and HLA-G as well as Neutrophil Extracellular Traps release could represent the underlying mechanisms of recurrent pregnancy loss, both spontaneous and after in vitro fertilization technique.

\section{Introduction}

Recurrent pregnancy loss (RPL) is an important reproductive health issue defined as two and more failed pregnancies and it represents one of the most frustrating and difficult areas in reproductive medicine because the aetiology is often unknown and there are few evidence-based diagnostic and treatment strategies $[1,2]$. There are several known causes of RPL as karyotype, endocrine, structural uterine abnormalities as well as immunologic causes [3]. During pregnancy the immune responses must be rigorously controlled since the maternal immune system is in close contact with the cells of the semi-allogenic fetus and a normal immunological homeostasis is needed to avoid reject of the fetus $[4,5]$.

\section{Interleukin 10 (IL-10)}

The anti-inflammatory cytokine interleukin 10 (IL-10) is secreted by various innate and adaptive immune cells, such as Th1/2 lymphocytes, B lymphocytes and macrophages [6]. The IL-10 produced by cytotrophoblasts and decidual $\mathrm{T}$ cells plays a crucial role in human reproduction regulating the fetal-placental immune interface [7-9]. Some single nucleotide polymorphisms (SNPs) in the proximal region of the IL-10gene were involved in the transcription rate of IL-10, directly affecting its production level
$[10,11]$. Among these, those correlated with the onset of abortive events are 1082 G/A, 819 C/T and 592 C/A [12]. The combinatorial haplotype of these 3 SNPs produces a lower plasma concentration of interleukin 10 in the bloodstream, resulting in pro-inflammatory signals at the placental maternal-fetal interface [13].

\section{Human Leucocyte Antigen-G (HLA-G)}

Human Leucocyte Antigen-G (HLA-G) molecules have immunomodulatory, anti-inflammatory and tolerogenic functions [14]. HLA-G antigens play a key role in immune suppression at the maternal-fetal interface, they are expressed primarily by cytotrophoblast cells during the first trimester of pregnancy [15] and protect the semi-fetal allograft from lysis by maternal NK cells [16]. Relatively high levels of circulating HLA-G in maternal blood have been observed throughout pregnancy [17-19]. It has been reported that two polymorphisms in the untranslated region 3 '(UTR) in exon 8, the insertion of 14 base pairs (bp) and the HLA-G G3142C polymorphism particularly affects the stability of HLA-G mRNA with lower levels or even absence of serum HLA-G [20-22]. This reduction leads to an immunological intolerance of the mother towards the embryo and therefore increases the probability of failure or abortion in the embryo implantation and recurrent miscarriage [23-26]. 


\section{Neutrophil Extracellular Traps (NETs)}

Upon infection of viruses, bacteria and fungi, neutrophils become activated and in addition to the well-known mechanisms of phagocytosis and degranulation, they can extrude neutrophil extracellular traps (NETs) with a multistep process termed NETosis [27-29]. NETs are extracellular webs composed by double stranded DNA and decondensed chromatin and they are enriched of citrullinated histone $\mathrm{H} 3$ along with granules of myeloperoxidase and neutrophil elastase [30]. In addition to their function as a host defence mechanism, a growing body of evidences indicate that NETS could have a role in promoting thrombosis [31], cancer metastases [32-35] as well as different immonological conditions such as systemic lupus erythematosus (SLE) [36] and rheumatoid arthritis (RA) [37]. NETs appear to be involved in various stages of the reproductive cycle, with a crucial role in fertility as well as recurrent pregnancy loss [38]. During pregnancy, placent can release inflammatory cytokines and debris activating neutrophils to form NETs, which may lead to an occlusion of the intervillous space and promote a condition of placental hypoxia leading to pregnancy loss [39]. Moreover, a growing area of research is now based on male factors that could be involved in the infertility. Neutrophils can interact with the semen in the female reproductive tract and in turn release NETs that could operate through a double effects consisting in phagocytize less motile spermatozoa or entrap them $[38,40]$.

\section{Conclusion}

Maternal immune system is crucial in recognizing the fetus as non-self. Genetic polymorphisms in immune key molecules such as IL-10 and HLA-G were associated with RPL and cortisone-based therapy at different posology could be used. Role of NETs in women experienced RPL should be taken in account also because these traps could interfere with the physiological role of spermatozoa, highlighting the importance also of the male partner in the RPL pathophysiology.

\section{Competing Interests}

No conflicts of interest exist.

\section{References}

1. El Hachem H, Crepaux V, May Panloup P, Descamps P, Legendre G, et al. (2017) Recurrent Pregnancy Loss: Current Perspectives. Int J WomensHealth 9:331-345.

2. Wani AA (2017) Relationship of insulin resistance with recurrent pregnancy loss. Int J ReprodContraceptObstetGynecol 6(4): 1312-1317.

3. Ibrahim Y, Johnstone E (2018) The male contribution to recurrent pregnancy loss. TranslAndrolUrol 7(Suppl 3): S317-S327.

4. Mizugishi K, Yamashita K (2017) Neutrophil Extracellular Traps Are Critical for Pregnancy Loss in Sphingosine Kinase-Deficient Mice on 129Sv/C57BL/6 Background. FASEB J 31(12): 5577-5591.

5. Shankar kumar U, Shankar kumar A, Chedda Z, Ghosh K (2011) Role of 14-bp Deletion/Insertion Polymorphism in Exon 8 of the HLA-G Gene in Recurrent Spontaneous Abortion Patients. J Hum ReprodSci 4(3): 143146.
6. Zhang TP, Tian Tian Lv, Shu Zhen Xu, Hai Feng Pan, Dong Qing Ye, et al. (2018) Association of interleukin-10 Gene Single Nucleotide Polymorphisms With Rheumatoid Arthritis in a Chinese Population. Postgrad Med J 94(1111): 284-288.

7. Zhang M, Xu J, Bao X, Niu W, Wang L, et al. (2017) Association Between Genetic Polymorphisms in Interleukin Genes and Recurrent Pregnancy Loss - A Systematic Review and Meta-Analysis. PLoS One 12(1): e0169891.

8. Pearson H (2002) Reproductive Immunology: Immunity's Pregnant Pause. Nature 420(6913): 265-266.

9. Fan DX, JieDuan, Ming Qing Li, Bin Xu, Da Jin Li, et al.(2011) The Decidual Gamma-Delta T Cells Up-Regulate the Biological Functions of Trophoblasts via IL-10 Secretion in Early Human Pregnancy. ClinImmunol 141(3): 284-292.

10. Eskdale J, Grant Gallagher, Cor L Verweij, Vivian Keijsers, Rudi G] Westendorp, et al. (1998) Interleukin 10 Secretion in Relation to Human IL-10 Locus Haplotypes. ProcNatlAcadSci USA 95(16): 9465-9470.

11. Mörmann M, Rieth H, Hua TD, Roupelieva, Hu, et al. (2004) Mosaics of Gene Variations in the Interleukin-10 Gene Promoter Affect interleukin-10 Production Depending on the Stimulation Used. Genes Immun 5(4): 246-255.

12. Zammiti W (2006) Association of $-592 \mathrm{C} / \mathrm{A},-819 \mathrm{C} / \mathrm{T}$ and $-1082 \mathrm{~A} / \mathrm{G}$ interleukin-10 promoter polymorphisms with idiopathic recurrent spontaneous abortion. Mol Hum Reprod 12(12): 771-776.

13. Edwards Smith CJ (1999) Interleukin-10 Promoter Polymorphism Predicts Initial Response of Chronic Hepatitis C to Interferon Alfa. Hepatology 30(2): 526-530.

14. Chiusolo P, S Bellesi, N Piccirillo, S Giammarco, S Marietti, et al, (2012) The Role of HLA--G 14-bp Polymorphism in allo-HSCT After Short-Term Course MTX for GvHD Prophylaxis. Bone Marrow Transplant 47(1): 120124.

15. Kovats S, Main EK, Librach C, Stubblebine M, Fisher SJ, et al. (1990) A Class I Antigen, HLA-G, Expressed in Human Trophoblasts. Science 248 (4952): 220-223.

16. D Almeida TC (2017) Soluble Human Leukocyte Antigen -G During Pregnancy and Infancy in Benin: Mother/child Resemblance and Association With the Risk of Malaria Infection and Low Birth Weight. PLoS One 12(2): e0171117.

17. Hunt JS (2000) Soluble HLA-G Circulates in Maternal Blood During Pregnancy. Am J Obstet Gynecol 183(3): 682-688.

18. Steinborn A, Tibor Varkonyi Alexander Scharf Franz Bahlmann Andreas Klee, et al. (2007) Early Detection of Decreased Soluble HLA-G Levels in the Maternal Circulation Predicts the Occurrence of Preeclampsia and Intrauterine Growth Retardation During Further Course of Pregnancy. Am J ReprodImmunol 57(4): 277-286.

19. Rizzo R, Andersen AS, Lassen MR, Sørensen HC, Bergholt T, et al. (2009) Soluble Human Leukocyte antigen-G Isoforms in Maternal Plasma in Early and Late Pregnancy. Am J ReprodImmunol 62(5): 320-338.

20. Hviid TV (2003) HLA-G Allelic Variants Are Associated With Differences in the HLA-G mRNA Isoform Profile and HLA-G mRNA Levels. Immunogenetics 55(2): 63-79.

21. Chen XY, Yan WH, Lin A, Xu HH, Zhang JG, et al. (2008) The 14 Bp Deletion Polymorphisms in HLA-G Gene Play an Important Role in the Expression of Soluble HLA-G in Plasma. Tissue Antigens 72(4): 335-341.

22. Martelli Palomino G (2013) Polymorphic Sites at the 3' Untranslated Region of the HLA-G Gene Are Associated With Differential Hla-G Soluble Levels in the Brazilian and French Population. PLoS One 8(10): e71742.

23. Monti M, Lupoli R, Sosa Fernandez LM, Cirillo F, Di Minno MND, et al (2019) Association of Human Leukocyte antigen-G 14 Bp Polymorphism With Recurrent Pregnancy Loss in European Countries: A Meta-Analysis of Literature Studies. FertilSteril 112(3): 577-585. 
24. Rousseau P (2003) The 14 Bp Deletion-Insertion Polymorphism in the 3' UT Region of the HLA-G Gene Influences HLA-G mRNA Stability. Hum Immunol 64(11): 1005-10010.

25. Enghelabifar M (2014) Association of the Maternal 14-bp Insertion/ Deletion Polymorphism in the Histocompatibility Leukocyte Antigen G Gene With Recurrent Implantation Failure. Iran J Reprod Med 12(9): 641-646.

26. Zidi I (2016) sHLA-G1 and HLA-G5 Levels Are Decreased in Tunisian Women with Multiple Abortion. Hum Immunol 77(4): 342-345.

27. de Oliveira S, Rosowski EE, Huttenlocher A (2016) Neutrophil Migration in Infection and Wound Repair: Going Forward in Reverse. Nat Rev Immunol 16(6): 378-391.

28. Mayadas TN (2014) The Multifaceted Functions of Neutrophils. Annu Rev Pathol 9: 181-218.

29. Delgado Rizo V, Martínez Guzmán MA, Iñiguez Gutierrez L, García Orozco A, Alvarado Navarro A, et al. (2017) Neutrophil Extracellular Traps and Its Implications in Inflammation: An Overview. Front Immunol 8: 81.

30. Brinkmann V (2004) Neutrophil Extracellular Traps Kill Bacteria. Science 303(5663): 1532-1535.

31. Fuchs TA(2010) Extracellular DNA Traps Promote Thrombosis. ProcNatlAcadSci USA 107(36): 15880-15885.

32. Cools Lartigue J, Spicer J, McDonald B, Gowing S, Chow S, et al. (2013) Neutrophil Extracellular Traps Sequester Circulating Tumor Cells and Promote Metastasis. J Clin Invest 123(8): 3446-3458.

ISSN: $2574-1241$

DOI: 10.26717/BJSTR.2020.27.004456

Marcello Monti. Biomed J Sci \& Tech Res

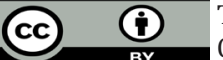

This work is licensed under Creative ommons Attribution 4.0 License

Submission Link: https://biomedres.us/submit-manuscript.php
33. Park J, Amoozgar Z, Maiorino L, Fein MR, Jorns J, et al. (2016) Cancer Cells Induce Metastasis-Supporting Neutrophil Extracellular DNA Traps. SciTransl Med 8(361): 361ra138.

34. Monti M, De Rosa V, Iommelli F, Carriero MV, Terlizzi C, et al. (2018) Neutrophil Extracellular Traps as an Adhesion Substrate for Different Tumor Cells Expressing RGD-Binding Integrins. Int J MolSci 19(8): 2350.

35. Monti M, Francesca Iommelli, Viviana De Rosa, Maria Vincenza Carriero, Roberta Miceli, et al. (2017) Integrin-dependent Cell Adhesion to Neutrophil Extracellular Traps Through Engagement of Fibronectin in Neutrophil-Like Cells. PLoS One 12(2): e0171362.

36. Dörne T(2012) SLE in 2011: Deciphering the Role of NETs and Networks in SLE. Nat Rev Rheumatol 8(2): 68-70.

37. Corsiero E, Michele Bombardieri, Emanuela Carlotti, Federico Pratesi, William Robinson, et al. (2016) Single Cell Cloning and Recombinant Monoclonal Antibodies Generation From RA Synovial B Cells Reveal Frequent Targeting of Citrullinated Histones of NETs. Ann Rheum Dis 75(10): 1866-1875.

38. Hahn S (2012) Neutrophil NETs in Reproduction: From Infertility to Preeclampsia and the Possibility of Fetal Loss. Front Immunol 3: 362.

39. Hahn S (2006) Disturbances in Placental Immunology: Ready for Therapeutic Interventions? Springer SeminImmunopathol 27(4): 477 493.

40. Alghamdi AS, Foster DN (2005) Seminal DNase Frees Spermatozoa Entangled in Neutrophil Extracellular Traps. BiolReprod 73(6): 11741181.

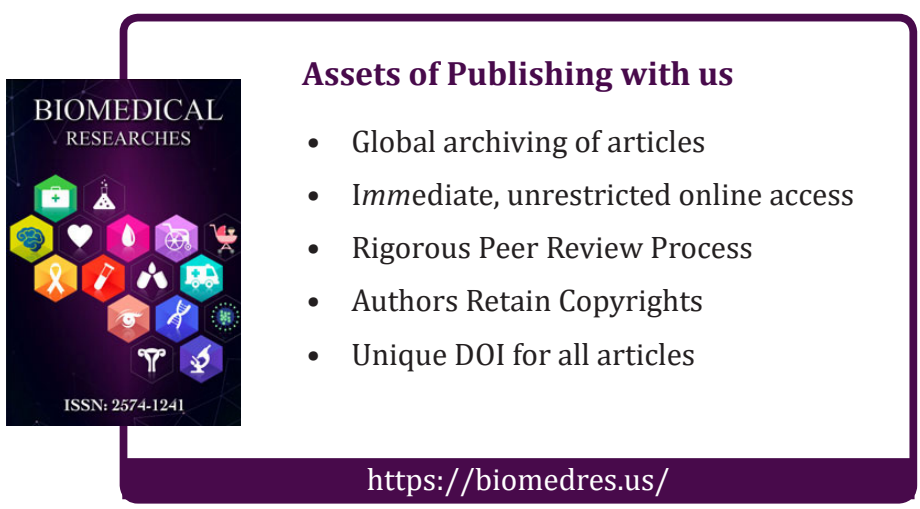

